\title{
Perceptions of Licensure: A Survey of Michigan Genetic Counselors
}

\author{
Jessica L. Mester • Angela M. Trepanier • \\ Cheryl E. Harper • Laura S. Rozek • \\ Beverly M. Yashar • Wendy R. Uhlmann
}

Received: 3 November 2007 / Accepted: 12 February 2009 /Published online: 19 May 2009

(C) National Society of Genetic Counselors, Inc. 2009

\begin{abstract}
This study by the Michigan Genetic Counselor Licensure Committee is the first known published documentation of genetic counselors' beliefs and attitudes about licensure. The response rate from genetic counselors in Michigan was 66\% (41/62). Ninety-five percent of respondents were supportive of licensure. Respondents believed licensure would legitimize genetic counseling as a distinct allied healthcare profession (97.5\%), increase the public's protection $(75 \%)$, and allow genetic counselors to practice independently (67\%). While $45 \%$ felt licensure would
\end{abstract}

J. L. Mester $(\bowtie)$

Genomic Medicine Institute, Cleveland Clinic,

9500 Euclid Ave., NE50,

Cleveland, OH 44195, USA

e-mail: mesterj@ccf.org

\section{A. M. Trepanier}

Wayne State University,

Detroit, MI, USA

C. E. Harper

Beaumont Hospital,

Royal Oak, MI, USA

L. S. Rozek • B. M. Yashar • W. R. Uhlmann

Department of Human Genetics, University of Michigan,

Ann Arbor, MI, USA

B. M. Yashar

Department of Ophthalmology and Visual Sciences,

University of Michigan,

Ann Arbor, MI, USA

W. R. Uhlmann

Department of Internal Medicine, Division of Molecular Medicine and Genetics, University of Michigan,

Ann Arbor, MI, USA increase counselor involvement in lawsuits, this did not impact licensure support $(p=0.744)$. Opinions were split regarding physician supervision and ordering tests. Even though $28 \%$ favored physician supervision, there was overwhelming support for genetic counselors performing some components of genetic testing (95\%) and ordering some types of genetic tests (82\%) independent of a physician. Use of this survey may be helpful in other states to assess genetic counselors' interest in licensure and for drafting legislation.

Keywords Licensure - Genetic counselors · Genetic counseling · Genetic testing · Survey · Supervision ·

Michigan

\section{Introduction}

Licensing is a process by which an agency of government grants permission to an individual to engage in a given occupation upon finding that the applicant has attained the minimal degree of competency required to ensure that the public's health, safety, and welfare will be reasonably well protected (Shimberg and Roederer 1978). Licensure for the practice of medicine has origins back to the Middle Ages when European rulers passed laws requiring an individual to undergo a specified amount of schooling, practice under the guidance of an experienced physician, take examinations, and pay a fee (Sigerist 1935). Today, licensure is a process regulated by each state and has strikingly similar criteria to those from the Middle Ages. Modern licensure laws have several components including eligibility criteria, description of a scope of practice, education and certification requirements, penalties for licensure violators, fees, and establishment of a licensure board. They restrict the use 
of title and practice of the profession to those individuals with specific training and certification. Licensing healthcare professionals provides the public a means of identifying which providers have adequate training to provide the services defined in the profession's scope of practice. The ultimate goal of licensure is to protect citizens from receiving services from untrained providers.

Genetic counselors hold Master's degrees and are nationally certified by the American Board of Genetic Counseling (ABGC). Prior to 1993, the American Board of Medical Genetics (ABMG) provided board certification for genetic counselors. The first mention of genetic counselor licensure occurred in the September 1979 issue of Perspectives in Genetic Counseling, a quarterly publication of the National Society of Genetic Counselors (NSGC) (Walker 1979). As of December 2008, genetic counselor licensure laws have been passed in seven states: California (2000), Utah (2001), Illinois (2004), Oklahoma (2006), Massachusetts (2006), Tennessee (2007), and New Mexico (2008) (National Conference of State Legislatures); efforts have been initiated in many other states. Genetic counselor licensure efforts in Michigan began informally in 1999 and in earnest in 2004 when the Michigan Genetic Counselor Licensure Committee, an ad hoc group of interested counselors, was established.

Obtaining licensure for a profession is a time-consuming multi-step process. A bill, once introduced, must be passed by the state House of Representatives and the Senate and finally signed into law by the Governor. Even for social workers, a well-established profession with a large number of practitioners, it has taken more than 20 years to obtain licensure laws in forty-eight states (Allain 2004). Licensure for Michigan social workers was not attained until 2004 (Michigan Social Workers' Licensing Act 2004). The NSGC has recommended that genetic counselors interested in licensure in their state first assess internal and external support (NSGC Guiding Principles for State Licensure Legislation). In the summer of 2004, the Michigan Genetic Counselor Licensure Committee decided to conduct a survey of the state's genetic counselors and $\mathrm{PhD}$ medical geneticists. The goals of this assessment were threefold:

1) To determine if Michigan genetic counselors and $\mathrm{PhD}$ medical geneticists support licensure;

2) To uncover any misconceptions about licensure; and

3) To gather opinions on issues that have proved controversial in other states, such as eligibility requirements, physician supervision, and ordering genetic tests independent of a physician.

In this paper, we report the results of this survey and discuss the implications for genetic counseling licensure in Michigan and nationally.

\section{Methods}

To develop the content of the Michigan survey instrument, genetic counselors listed in the members-only section of the NSGC website (www.nsgc.org) as contacts for the 18 states that had initiated licensure efforts as of July 3, 2004 were emailed for input. Survey instruments and written information on licensure were requested; at that time, only Texas and California had surveyed their genetic counselors on this issue. The survey instrument from Texas was used to develop the initial framework for the Michigan survey instrument. Members of the Michigan Genetic Counselor Licensure Committee, NSGC Ad Hoc Licensure Subcommittee, and University of Michigan faculty members involved with the study were asked to provide input on survey content and format. These individuals are cited in the "Acknowledgements" section of this paper.

The final survey instrument was comprised of 36 questions in three sections: demographic information (10 questions), potential bill language (18 questions), and thoughts on licensure ( 8 questions). Demographic information included certification status, years of experience, degree, gender, primary role, specialty area, employment setting and supervisor. Language in a potential bill included questions regarding eligibility, certification, examination and continuing education requirements, temporary licenses, ordering genetic testing, supervision, and types of genetic counseling roles that should be included in a licensure law. Thoughts on licensure examined respondents' level of support and beliefs about licensure and reasons to support or oppose licensure. Most questions were multiple-choice with an open-ended option. Supplementary information was provided with the survey instrument that pertained to specific survey questions and included explanations about genetic counseling licensure, purpose of licensure, licensure eligibility, temporary licenses, supervision, and ordering genetic tests. Additionally, comparisons of the language of the genetic counseling licensure bills passed in California, Utah, and Illinois as well as a history of genetic counseling licensure efforts nationally and in Michigan were provided. The study was approved January 19, 2005 by the Institutional Review Board at the University of Michigan (IRBMED\# 2004-0891). The survey instrument and supplemental background material can be found by accessing the Michigan Association of Genetic Counselors' website (www.magcinc.org) and following the link to "Genetic Counselor Licensure". The survey instrument was sent to genetic counselors and $\mathrm{PhD}$ medical geneticists in the state of Michigan as identified through the NSGC membership database (http://www.nsgc.org/ source/Members/cMemberSearch.cfm), The Genetics Societies Membership Directory (http://www.ashg.org/ pages/member_search.shtml), a list of genetics professionals 
maintained by the Michigan Department of Community Health, and through personal contacts of members of the Michigan Genetic Counselor Licensure Committee. We believe these resources identified all genetic counselors and $\mathrm{PhD}$ medical geneticists in Michigan. PhD medical geneticists were included in the study and given the same survey instrument because the genetic counseling licensure laws in Utah and Illinois included $\mathrm{PhD}$ medical geneticists as qualified to obtain a genetic counseling license (Utah Genetic Counselors Licensing Act 2001; Illinois Genetic Counselor Licensing Act 2004). Unless otherwise specified, the responses from the $\mathrm{PhD}$ medical geneticists are grouped with those of the genetic counselors.

The survey was sent on January 26, 2005, with a second reminder on February 7, 2005 to a total of 62 persons (61 by electronic mail and one by postal mail because no electronic mail address was available). Fifty-nine of these individuals were genetic counselors and three were $\mathrm{PhD}$ medical geneticists. The survey deadline was February 11, 2005. To ensure anonymity, once a completed survey was received via e-mail, it was printed without any identifying information and the original e-mail was deleted. Likewise, responses received via postal mail were separated from their mailing envelopes, which were then discarded. Results were analyzed using Statistical Package for the Social Sciences (SPSS) version 13.0. Chi-square and Fisher exact tests were used to evaluate differences in responses between groups. Odds ratios and 95\% confidence intervals were calculated to determine the magnitude of the association between groups. Fisher's exact tests were used when data had small $(\mathrm{n}<5)$ cell size. P-values less than or equal to 0.05 were defined as statistically significant; p-values between 0.05 and 0.10 were defined as trends.

\section{Results}

\section{Demographic Information}

The demographics of the sample population, with a comparison (where applicable) to the 2004 demographic profile of genetic counselors who were members of the National Society of Genetic Counselors (based on the 2004 NSGC Professional Status Survey) is summarized in Table 1. Within three weeks, 41 completed surveys were received, 38 via e-mail and 3 via postal mail, for a response rate of $66 \%$ (41/62). Responses from one individual who had not been practicing in Michigan for over five years were excluded from the data analysis.

All respondents were female and most had been practicing as genetic counselors for either five to ten (12/ $39,30.8 \%)$ or ten to fifteen $(9 / 39,23.1 \%)$ years. Counselors participating in this study were a more experienced group than the national average (Table 1). Sixty-seven percent (27/40) of respondents were board certified genetic counselors, 25\% (10/40) had active candidate status with the American Board of Genetic Counseling and 3 (7.5\%) were certified $\mathrm{PhD}$ medical geneticists. All 10 of the genetic counselors with active candidate status had less than three years of experience. The majority of survey respondents $(72 \%, 29 / 40)$ held clinical roles. Of these, $41 \%$ worked in prenatal genetics, $41 \%$ in pediatrics genetics, $24 \%$ in cancer genetics, $21 \%$ in adult genetics and 3\% in metabolic clinics. These responses total more than $100 \%$ because some indicated primary involvement in more than one clinic type. Fifty-eight percent (22/38) of respondents worked at university medical centers. Twenty-five percent (10/40) of respondents participated in outreach clinics. Respondents' primary supervisors were mainly clinical geneticists (39\%), non-geneticist physicians (28\%), and $\mathrm{PhD}$ medical geneticists $(20 \%)$.

\section{Thoughts on Licensure}

Overall, the majority of respondents were either strongly supportive $(19 / 40,47.5 \%)$ or supportive $(19 / 40,47.5 \%)$ of licensure for genetic counselors. Given that the total number of genetic counselors in Michigan at the time of the study was 62, even if all the nonrespondents were against licensure, this result demonstrates that a majority of counselors in the state $(61 \%, 38 / 62)$ were supportive. Notably, no respondents were opposed to licensure and none indicated that there was no need for licensure. The majority of respondents $(33 / 40,82.5 \%)$ felt there is a need for genetic counseling to be a licensed profession in Michigan; the remaining seven respondents (17.5\%) replied "I don't know." Board-certified counselors were approximately six times more likely than counselors with active candidate status to be strongly supportive (vs. supportive) of licensure $(p=0.032)$. Meaningful correlations between practice setting and support could not be made given that the limited number of providers in each setting resulted in large confidence intervals.

Respondents supportive of licensure indicated that their top two reasons for support were to "legally ensure that only individuals with the appropriate education are providing the public with information about their genetic risks", $(27 / 37,73 \%)$ and to "further legitimize genetic counseling as a distinct allied healthcare profession" (20/37, 54\%) (Table 2).

To ascertain beliefs about licensure, questions were asked regarding how respondents felt licensure may impact four areas: public protection, legitimizing genetic counseling as a distinct allied healthcare profession, lawsuit involvement, and independent practice. A majority of respondents saw licensure positively and felt that it would 
Table 1 Demographic Information
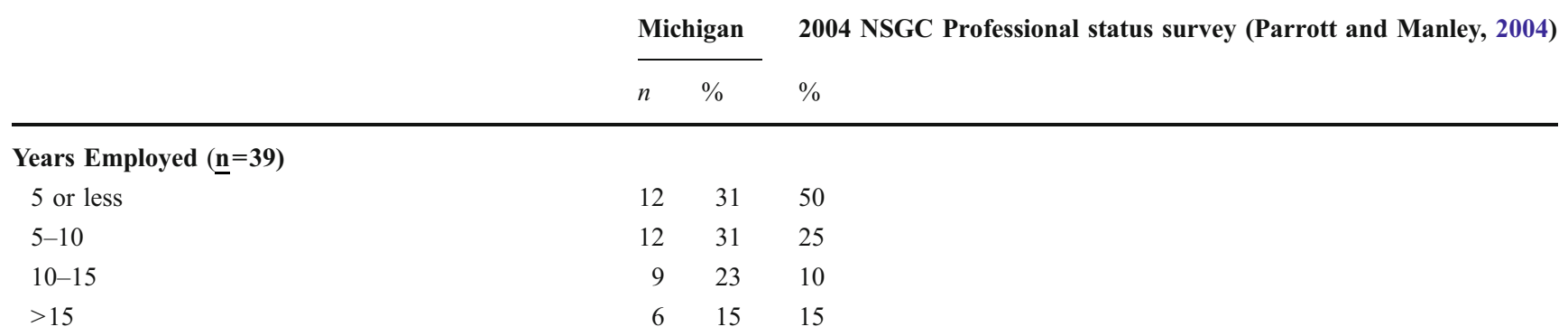

Certification Status $(\underline{n}=40)$

ABGC-certified genetic counselor

ABGC-eligible genetic counselor

ABMG-certified PhD medical geneticist

Primary Role $(\underline{n}=40)^{a}$

$\begin{array}{lrrl}\text { Clinical } & 29 & 72.5 & 83 \\ \text { Research/Study Coordinator } & 5 & 12.5 & 32 \\ \text { Teaching/Education/Supervising students } & 3 & 7.5 & 54 \\ \text { Public health/Public policy } & 2 & 5 & 2 \\ \text { Laboratory Consultant } & 1 & 2.5 & \text { NS } \\ \text { Primary Practice Area (clinical only, } \underline{\mathbf{n}}=\mathbf{2 9})^{\mathbf{a}, \mathbf{b}} & & & \\ \text { Prenatal } & 12 & 41 & 55 \\ \text { Pediatrics } & 12 & 41 & 36 \\ \text { Cancer } & 7 & 24 & 39 \\ \text { Adult } & 6 & 21 & 24 \\ \text { Other: Metabolic } & 1 & 3 & \text { NS } \\ \text { Primary Employment Setting }(\underline{\mathbf{n}}=\mathbf{3 8}) & & & \\ \text { University Medical Center } & 22 & 58 & 41 \\ \text { Private Hospital/Medical Facility } & 11 & 29 & 21 \\ \text { Public Hospital/Medical Facility } & 2 & 5 & 11 \\ \text { State Health Department } & 2 & 5 & 3 \\ \text { Diagnostic Laboratory } & 1 & 3 & 7 \\ \text { Primary Supervisor (genetic counselors only, } \mathbf{n}=\mathbf{3 6}) & & & \text { NS }\end{array}$

$\begin{array}{lll}12 & 31 & 50\end{array}$

$\begin{array}{lll}12 & 31 & 25\end{array}$

$9 \quad 23 \quad 10$

$\begin{array}{lll}6 & 15 & 15\end{array}$

$27 \quad 67.5$

$10 \quad 25$

$3 \quad 7.5$

Cinical geneticist

$14 \quad 39$

$\begin{array}{lrr}\text { PhD medical geneticist } & 7 & 19 \\ \text { Genetic counselor } & 1 & 3\end{array}$

Non-clinical geneticist physician $\quad 10 \quad 28$

None $\quad 1 \quad 3$

Other: PhD molecular biologist, Department chair $\quad 3 \quad 8$

Outreach Participation $(\underline{\mathbf{n}}=\mathbf{4 0})$

Yes

No

Gender $(\underline{n}=40)$

$\begin{array}{lrcc}\text { Female } & 40 & 100 & 95 \\ \text { Male } & 0 & 0 & 5\end{array}$

$\mathrm{NS}=$ not surveyed

${ }^{a}$ NSGC Professional Status Survey respondents were allowed to select more than one response

${ }^{\mathrm{b}}$ Some respondents marked more than one category

("N" for each demographic variable varies slightly as not all respondents answered all questions.) 
Table 2 Reasons to Support Licensure ( $\underline{n}=37$ )

\begin{tabular}{|c|c|c|c|c|}
\hline & \multicolumn{2}{|c|}{$1^{\text {st }}$ choice } & \multicolumn{2}{|c|}{$2^{\text {nd }}$ choice } \\
\hline & $n$ & $\%$ & $n$ & $\%$ \\
\hline $\begin{array}{l}\text { "I feel it is necessary to legally ensure that only individuals with the appropriate education are providing } \\
\text { the public with information about their genetic risks." }\end{array}$ & 20 & 54 & 7 & 19 \\
\hline "I believe licensure would further legitimize genetic counseling as a distinct allied healthcare profession." & 10 & 27 & 10 & 27 \\
\hline "I feel it is important for genetic counseling to be 'in-line' with other healthcare professions that require a license." & 4 & 11 & 7 & 19 \\
\hline "I believe it is necessary to have a legal definition for who may and may not use the job title 'genetic counselor"." & 3 & 8 & 10 & 27 \\
\hline $\begin{array}{l}\text { "I feel it is necessary to have an enforceable method of penalization for those who violate ethical standards } \\
\text { of practice." }\end{array}$ & 0 & 0 & 2 & 5 \\
\hline "I believe licensure will protect genetic counselors from litigation." & 0 & 0 & 0 & 0 \\
\hline Other: "For billing purposes." & 0 & 0 & 1 & 3 \\
\hline
\end{tabular}

legitimize genetic counseling as a distinct allied healthcare profession $(39 / 40,97.5 \%)$, increase the public's protection $(30 / 40,75 \%)$, and give genetic counselors the ability to practice independently $(26 / 40,67 \%)$. A majority (21/40, $52.5 \%$ ) did not think licensure would impact genetic counselors' involvement in lawsuits, while 45\% (18/40) felt that licensure would increase this risk. Importantly, this variable did not influence strength of support for licensure $(p=0.744)$. Respondents believing that licensure would increase genetic counselors' lawsuit involvement continued to show strong support for licensure.

\section{Language in a Potential Bill}

All respondents felt that $\mathrm{ABMG}$ or $\mathrm{ABGC}$-certified genetic counselors should be eligible to obtain a genetic counseling license. When asked which roles should be included in a licensure law, 100\% (40/40) responded that clinical roles should be included, followed by laboratory consultant roles (36/40, 90\%), teaching/education/student supervision roles (32/ $40,80 \%$ ), public health/public policy roles $(27 / 40,67.5 \%)$, and research/study coordinator roles (27/40, 67.5\%). Twenty-five individuals $(62.5 \%)$ selected all of these categories.

Most respondents $(37 / 39$, 95\%) felt that the American Board of Genetic Counseling (ABGC) examination should be used as a licensing examination and that the requirements for continuing education should match ABGC requirements for re-certification $(36 / 38,95 \%)$. A majority (30/39, 77\%), including all of the respondents with active candidate status, also felt there was a need for some genetic counselors to have temporary licenses. All respondents who felt temporary licenses were necessary indicated that genetic counselors with active candidate status should have temporary licenses.

Within the group who felt temporary licenses were necessary, 97\% (28/29) indicated they should be valid only as long as the genetic counselor is eligible for active candidate status with the ABGC. Most respondents (18/29, $62 \%$ ) also felt that $\mathrm{ABMG}$-eligible $\mathrm{PhD}$ medical geneticists should be eligible for a temporary license.

Respondents were divided on whether or not fullylicensed genetic counselors should require supervision. Twenty-eight percent (11/40) answered "Yes", 47.5\% (19/ 40) answered "No", and 25\% (10/40) responded "I don't know." Of the respondents who supported a supervision requirement, all felt that board-certified clinical geneticists would be qualified to fill this role, followed by "subspecialty physicians board-certified in the clinical area where the genetic counselor is working" $(10 / 11,91 \%)$ and "ABMG-certified Ph.D. medical geneticists" (9/11, 82\%). Respondents were more likely to indicate that genetic counselors with a temporary license should have additional supervision. Sixty-two percent (25/40) answered "Yes", 25\% (10/40) answered "No", and 12.5\% (5/40) responded "I don't know". Of the respondents who answered "Yes", board-certified clinical (MD) geneticists again were the top choice for who may supervise $(24 / 25,96 \%)$, followed by fully-licensed genetic counselors and board-certified $\mathrm{PhD}$ medical geneticists, each chosen by $84 \%$ (21/25) of respondents. Supervision by subspecialty physicians boardcertified in the genetic counselor's clinical area was selected by $68 \%(17 / 25)$.

When survey respondents were asked about private practice for genetic counselors, a majority $(28 / 40,70 \%)$ responded that they were supportive. Two respondents $(5 \%)$ indicated that they were not supportive, and 25\% (10/40) responded "I don't know". Respondents who reported having a primarily clinical role were approximately six times less likely to support private practice that those in other roles $(p=0.076)$.

Another pair of questions assessed respondents' attitudes surrounding the autonomy of genetic counselors in the areas of facilitating and ordering genetic testing independent of a physician. The first question asked which components of genetic testing fully-licensed counselors 
Table 3 Ordering Genetic Tests: Which components should genetic counselors be able to perform independent of a physician? $(\underline{\mathrm{n}}=39)$

\begin{tabular}{lll}
\hline & $n$ & $\%$ \\
\hline Deciding which laboratory's testing services to utilize. & 37 & 95 \\
Obtaining informed consent from patients. & 37 & 95 \\
Interpreting genetic test results for patients. & 32 & 82 \\
Deciding which genetic test to order. & 30 & 77 \\
Ordering the genetic test in the genetic counselor's name. & 26 & 67 \\
At least one, but not all, of the above & 23 & 59 \\
All of the above & 14 & 36 \\
\hline
\end{tabular}

should be able to perform independently (Table 3 ). Of the 39 respondents to this question, two $(5 \%)$ indicated that they did not feel genetic counselors should be able to perform any components independently. While support was strong for autonomy in individual steps in the genetic testing process, only $36 \%(14 / 39)$ felt that genetic counselors should be able to independently perform all of the specified components and 59\% (23/39) indicated that genetic counselors should be able to perform some (at least one) components independently. Of those who chose some or all components $(\mathrm{n}=37)$, all felt that counselors should be able to decide which laboratory's testing services to utilize and obtain informed consent. Those who responded that fully-licensed genetic counselors do not need physician supervision were significantly more likely to indicate that genetic counselors should be able to perform all versus some of these components of genetic testing independently $(p=0.010)$.

The second question in this series asked what types of genetic tests a genetic counselor should be able to order independent of a physician (Table 4). Overall, $82 \%(31 / 38)$ indicated that genetic counselors should be able to order at least one or more of these tests independently. Eleven of 38 respondents $(29 \%)$ felt that genetic counselors should be able to order all of these types of tests independently, whereas $53 \%$ (20/38) felt that genetic counselors should be able to order just a subset of these tests independently. Of

Table 4 Ordering genetic tests: What types should genetic counselors be able to order independent of a physician? $(\underline{n}=38)$

\begin{tabular}{lll}
\hline & $n$ & $\%$ \\
\hline Carrier testing & 31 & 82 \\
Prenatal screening tests & 30 & 79 \\
Predictive genetic testing & 20 & 53 \\
Presymptomatic genetic testing & 19 & 50 \\
Fetal diagnostic tests & 16 & 42 \\
Diagnostic genetic testing for adults & 15 & 39 \\
Diagnostic genetic testing for children & 14 & 37 \\
At least one, but not all, of the above & 20 & 53 \\
All of the above & 11 & 29 \\
\hline
\end{tabular}

those who felt that genetic counselors should be able to order at least some of the types of genetic tests, all felt that genetic counselors should be able to order carrier screening independent of a physician. All ten of the respondents participating in outreach clinics felt that genetic counselors should be able to order all or some of these types of tests independently.

Of note, those who did not support physician supervision of fully-licensed genetic counselors were more likely to respond that counselors should be able to order some types of tests independently although this did not reach statistical significance $(p=0.068)$. This trend is similar to that observed for the previous question focusing on testing components.

\section{Discussion}

This is the first known study to examine genetic counselors' beliefs and attitudes about licensure. The study demonstrated that a majority of the genetic counselors in the state of Michigan support genetic counseling licensure. Boardcertified counselors were more likely to strongly support licensure. This difference may simply be the result of certification status. However, since the certified counselors had more experience (all more than three years) than those with active candidate status (all less than three years) we cannot rule out the possibility that years of experience had an influence on how respondents answered this question. Respondents indicated that the main reasons they supported licensure were to further legitimize genetic counseling as a distinct allied healthcare profession and to help protect the public. It was interesting to note that while almost half of respondents felt that licensure would increase the risk for lawsuits, this did not detract from their support for licensure.

Overall, the demographic profile of the Michigan counselors who took part in this study was comparable to that published in the 2004 NSGC Professional Status Survey. A national survey would be required to fully assess how generalizable these results are to the perceptions of genetic counselors across the country. The two main differences observed were in years of experience in genetic 
counseling and board certification status. A nationwide survey would include a higher proportion of less experienced counselors $(50 \%$ with less than 5 years experience versus 31\% in our population) (Parrott and Manley 2004) and a small number of genetic counselors who are neither board-certified nor board-eligible. As a result of these demographic differences, support for licensure on a national level may not be as strong as we found in our study.

The views of our survey respondents on eligibility, continuing education requirements, and temporary licensure were consistent with the currently existing genetic counselor licensure laws (National Conference of State Legislatures). All respondents felt that board-certified genetic counselors should be eligible to obtain a genetic counseling license. $\mathrm{ABGC}$ or $\mathrm{ABMG}$ certification is an eligibility requirement in Utah, Illinois, Oklahoma, Massachusetts, and Tennessee. Ninety-five percent of respondents in our study felt that the ABGC examination should be used as a licensing examination and that the requirements for continuing education should match ABGC requirements for re-certification. All states that have passed licensure laws and are actively licensing genetic counselors are using the ABGC or ABMG certification examination as the licensing examination. A strong majority of respondents felt there was a need for some genetic counselors to have temporary licenses, which should be valid only as long as the genetic counselor has active candidate status with the ABGC. This is again consistent with the licensure laws that have been passed and enacted.

There was significant divergence of opinions about whether or not physician supervision should be required for fully-licensed genetic counselors. Although almost half (47.5\%) were opposed to supervision, $27.5 \%$ of respondents believed supervision should be required and $25 \%$ selected "I don't know" as a response. A limitation of this finding is that the definition of supervision and what it entails on a practical basis was not provided and thus might have been interpreted in varied ways by respondents. To date, supervision for fully licensed genetic counselors has not been required in states with licensure laws, although the Illinois and Tennessee laws require a physician referral for genetic counseling. NSGC recommends that supervision only be required for genetic counselors with temporary licenses (NSGC Guiding Principles for State Licensure Legislation). In Michigan, only physician's assistants have a supervision requirement written into their licensure law. The practice of a physician's assistant is defined as "the practice of allopathic or osteopathic medicine under the supervision of an allopathic or osteopathic physician" (Michigan Task Force on Physician's Assistants 1978). Physician's assistants sought supervision as a requirement in their licensure law so that they would have the freedom to perform the same tasks as a physician. Without a supervision requirement, licensure for this group likely would not have been supported by the Michigan State Medical Society because of scope of practice issues (Goldman 2004).

The National Society of Genetic Counselors' Scope of Practice (approved June 2007 and available at www.nsgc. org) does not stipulate supervision for genetic counselors. The Scope of Practice does state, however, that genetic counselors "... discuss case information with other members of the healthcare team as necessary..." and "recognize personal limitations in knowledge and/or capabilities and seek consultation or appropriately refer clients to other providers." With regard to genetic testing, the Scope of Practice states that genetic counselors "Order tests and perform assessments in accordance with local, state, and federal regulations." As such, the Scope of Practice for genetic counselors recognizes that the authority to make more specific decisions regarding supervision and genetic testing lies in the hands of individual institutions, state licensure laws, and/or federal legislation. With regard to licensure laws, each state is empowered to craft language that best suits the needs of its stakeholders with regard to these critical issues.

While licensure bills have addressed supervision of genetic counselors with temporary licenses, there have not been stipulations for genetic counselors with full licenses. It was not surprising that all respondents who supported a supervision requirement felt that board-certified clinical geneticists were appropriate for this role. While the level of support was less than that found for clinical geneticists, it was notable that respondents felt similarly favorable about having subspecialty physicians and $\mathrm{PhD}$ medical geneticists provide this supervision. This may reflect the fact that an increasing number of genetic counselors work on healthcare teams without MD or PhD geneticists and that they value the expertise of these non-genetics specialists. According to data from the ABMG, there are 22 states with ten or fewer clinical geneticists (http://www.abmg.org/pdf/ SpecalistsByState.pdf). Given the limited number of geneticists, if supervision is written into licensure language, requiring that these practitioners provide it would limit the number of genetic counselors who could practice and potentially reduce access to services.

In terms of supervision of those with temporary licenses, survey respondents most strongly supported clinical geneticists, licensed genetic counselors, and physicians boarded in the subspecialty in which the genetic counselor was practicing as potential supervisors for genetic counselors with temporary licenses, which is consistent with most of the licensure laws that have been passed. For genetic counselors with temporary licenses, laws in Utah, Massachusetts, and Tennessee stipulate that supervision can be provided by a licensed genetic counselor or ABMGcertified physician. In Oklahoma, Illinois, and New Mexico 
ABMG certification is not specified; supervision of genetic counselors with temporary licenses can be provided by any physician licensed to practice in the state or a licensed genetic counselor (National Conference of State Legislatures). This may be perceived as a subtle difference, but in a state where there are few clinical geneticists, allowing counselors with temporary licenses more supervision options allows greater access to genetic counseling services.

A notable difference in the consideration of who may supervise counselors with temporary licenses was that all geneticists- $\mathrm{MD}, \mathrm{PhD}$, and genetic counselors - were selected more often than subspecialty physicians, who were a top choice to supervise licensed counselors. Again, respondent numbers were not high enough to derive statistical significance, but it is possible that respondents recognized the difference in genetics expertise between counselors qualifying for temporary licensure and their ABGC or ABMG-certified colleagues and felt it was important for them to be supervised by an ABGC or ABMG-certified professional.

Diverse opinions were noted regarding genetic counselors' roles in genetic testing. Although a majority of respondents felt that genetic counselors should not be able to order all types of genetic tests independent of a physician, there were some tests (carrier testing, prenatal screening tests, predictive testing, presymptomatic testing) that a majority felt they should be able to order. In contrast, a majority indicated that a physician should be involved in diagnostic testing (fetal, adult, and child diagnostic testing). This may reflect an appreciation of the limit of the genetic counselors' scope of practice, which does not include making diagnoses. It was not surprising that counselors involved in outreach clinics were all supportive of genetic counselors ordering at least some types of genetic tests independently. Given the limited number of times outreach clinics are held and the potential absence of a physician on site, having the ability to order genetic tests could increase clinic efficiency and potentially facilitate increased patient access to genetic services.

Ordering genetic tests has not been stipulated in any of the genetic counselor licensure bills that have been passed and has been explicitly prohibited in the Illinois law. If the Michigan genetic counselor licensure act included ordering genetic tests under its scope of practice, the physicians' lobby may require supervision of fully licensed genetic counselors before agreeing to support the bill. In addition, given the rapid pace of change in genetic and genomic medicine, defining what constitutes a genetic test and deciding which types of tests could be ordered by genetic counselors would be difficult to specify in a licensure law.

Related to the issue of ordering tests independently, respondents had varying opinions regarding practicing independently (private practice). Genetic counselors having a primarily clinical role tended to be less supportive of private practice than counselors working primarily in nonclinical areas. Although this association was not statistically significant, it seemed notable in light of the idea that perhaps clinical genetic counselors are more likely to recognize the value of complementary physician expertise and the benefits of working as a member of a health care team which they do not feel would exist in a private practice setting.

Given that respondents were overwhelmingly in favor of genetic counseling licensure, it came as no surprise that most also shared positive beliefs about the impact licensure might have on three areas: legitimizing genetic counseling as a distinct allied healthcare profession, public protection, and independent practice. Regarding independent practice, it's important to note that while licensure may make genetic counselors feel more empowered to pursue private practice opportunities, in reality it is already possible for a genetic counselor in any state to do so. In some states licensure is a necessary criterion for a provider to be reimbursed by a hospital or third-party payor, thereby making a private practice more likely to succeed.

Questions dealing with billing and reimbursement were intentionally excluded from this study. The goal of this survey was to obtain opinions on licensure without introducing questions that would shift the focus towards billing and reimbursement implications and away from the primary purpose of licensure, which is public protection. Although licensure may improve the outlook for reimbursement, it does not guarantee that third-party payors will reimburse for a profession's services. This survey did not assess whether respondents perceived a link between licensure and the ability to bill independently and whether such a perception had an impact on support for licensure. Had genetic counselors had been surveyed on this issue and found to support licensure primarily for billing purposes, this would have emphasized a need to educate them regarding the primary purpose of licensure. Ensuring that genetic counselors understand the purpose of licensure legislation is critical in promoting effective lobbying efforts.

The chief limitations of this study were small sample size and lack of information on non-respondents. Small sample size limited the capacity for complex statistical analyses; as a result, this is primarily a descriptive study. The fact that nearly all respondents were supportive of licensure for genetic counselors does not guarantee that non-respondents are supportive as well. Of note, there were no respondents who reported being neither ABGC/ABMGcertified nor ABGC-eligible. Individuals falling into this category would become unable to legally refer to themselves as genetic counselors. In addition, genetic counselors could face employment difficulties or potential dismissal if licensure was a job requirement and certification or active candidate status was a prerequisite for licensure. In 
Tennessee a grandfathering clause was added to the licensure law to allow genetic counselors with many years of experience but no certification to be eligible for a license following an evaluation of their work history, scope of practice, and potentially other factors (Tennessee Genetic Counselors' Licensing Act 2007).

A final limitation of the study was the sub-optimal wording of some survey questions. Some of the terminology used, specifically "supervision", "independent", and "private practice" were not defined and could have been interpreted in various ways by respondents. For example, some respondents may have interpreted "independent" as working in a private practice setting while others may have thought this meant working autonomously but within the context of a healthcare team. Despite the noted limitations, this study was successful in achieving its stated goals.

\section{Conclusions}

The purpose of licensure is to protect the public by defining who is qualified to present themselves as a genetic counselor. Without state regulation, anyone can use the title "genetic counselor", practice without physician supervision, and potentially be reimbursed for services with or without a physician referral. However, a licensure law can also limit the practice of a state's genetic counselors by narrowing the profession's definition in the language of the bill.

The results of this survey documented significant support of licensure (95\%) for genetic counselors in Michigan and have been useful in guiding Michigan's licensure effort. In addition, the survey identified areas of consensus and areas requiring further discussion with regard to the content of and stipulations within licensure legislation. Specific areas that proved controversial included supervision and ordering genetic tests. Respondents' views from our survey regarding professional qualifications and continuing education are consistent with existing genetic counselor licensure laws. Our experience from this study has been used to develop a survey for clinical geneticists and physician specialists who provide genetic services in Michigan (Pierce et al. 2007).

Given the response rate of $66 \%$, we believe these results are representative of genetic counselors in Michigan. In addition, given the demographic similarity to genetic counselors as reported in the 2004 NSGC Professional Status Survey, we also believe these results are likely similar to those of genetic counselors across the United States. However, as already noted, demographic differences in years of experience and certification status could affect views and level of support for licensure. Our survey of Michigan genetic counselors yielded results that have been useful for licensure efforts. Use of this survey may be helpful in other states to assess genetic counselors' interest in licensure, identify controversial issues to resolve, and for drafting legislation.

Acknowledgements This study was completed in partial fulfillment of the requirements for the first author's Master of Science degree from the University of Michigan. The first author was awarded funding for this work through the James V. Neel Genetic Counseling Fellowship. The authors would like to recognize the following individuals for their assistance with the drafting of the survey instrument: members of the NSGC licensure subcommittee, especially Sara Goldman, MPH, Daniel Riconda, MS, Christine Miller, MS and Karen Potter, MS; members of the Michigan Genetic Counseling Licensure Committee, especially Helga Toriello, $\mathrm{PhD}$, Rajani AatreKeshavamurthy, MS and Jacquelyn Riley, MS; and University of Michigan research committee members Edward Goldman, JD, and Cleopatra Caldwell, PhD.

\section{References}

Allain, D. (2004). Presidential address 2003: NSGC living life forward. Journal of Genetic Counseling, 13, 1-7.

Goldman, E. (2004). Personal Communication.

Illinois Genetic Counselor Licensing Act (2004). Retrieved January 19, 2009 from http://www.ilga.gov/legislation/ilcs/ilcs3.asp? ActID $=2632 \&$ ChapAct $=225 \% 26$ nbsp $\% 3$ BILCS $\% 26$ nbsp $\%$ $3 \mathrm{~B} 135 \% 2 \mathrm{~F} \&$ ChapterID $=24 \&$ ChapterName $=$ PROFESSIONS + AND + OCCUPATIONS\&ActName $=$ Genetic + Counselor + Licensing + Act $\% 2 \mathrm{E}$

Michigan Social Workers' Licensing Act. (2004). Retrieved January 19, 2009 from http://www.legislature.mi.gov/documents/20032004/publicact/pdf/2004-PA-0061.pdf

Michigan Task Force on Physician's Assistants. (1978). Retrieved January 19, 2009 from http://www.michigan.gov/mdch/0,1607,7132-27417 $27529 \quad 27550-59188-, 00 . h t m l$

National Conference of State Legislatures. Retrieved January 19, 2009 from http://www.ncsl.org/programs/health/genetics/ gencoun.htm

National Society of Genetic Counselors Guiding Principles for State Licensure Legislation. Retrieved January 19, 2009 from http:// www.nsgc.org/members_only/licensure/index.cfm.

Parrott, S., and Manley, S. (2004). NSGC Professional Status Survey. Retrieved January 19, 2009 from http://www.nsgc.org/careers/ 2004_PSS_Final_pw.pdf.

Pierce, K., Marvin, M., Harper, C., Trepanier, A., Rozek, L., Uhlmann, W. (2007). Licensure of Genetic Counselors: A Survey of Michigan Genetic Service Providers. Contributed Paper Presentation at the NSGC Annual Education Conference, October 15, 2007.

Shimberg, B., \& Roederer, D. (1978). Occupational Licensing: Questions a Legislator Should Ask. The Council of State Governments; Lexington, KY.

Sigerist, H. E. (1935). The history of medical licensure. Journal of the American Medical Association, 104, 1057-9.

Tennessee Genetic Counselors' Licensing Act. (2007). Retrieved January 19, 2009 from http://www.capitol.tn.gov/legislation/ Archives/105GA/bills/BillStatus/SB0935.htm

Utah Genetic Counselors Licensing Act (2001). Retrieved January 19, 2009 from http://le.utah.gov/ code/TITLE58/58_75.htm

Walker, A. (1979). Asilomar east. Perspectives in Genetic Counseling, $3,1-4$. 